\title{
MATTER(S) OF INTEREST: ARTEFACTS, SPACING AND TIMING
}

\author{
by \\ Tim Schwanen
}

Schwanen, T., 2007: Matter(s) of interest: Artefacts, spacing and timing. Geogr. Ann., 89 B (1): 9-22.

\begin{abstract}
This paper argues that time-geography can make a contribution to contemporary 'rematerialized' geographies, because the interconnections among social processes, human corporeality and inanimate material artefacts within the landscape were among Hägerstrand's central concerns. Time-geography needs none the less to be extended in several ways to make it more reconcilable with current thinking about materiality in geography. The possibility of combining Hägerstrand's framework with notions from (post) actor-network approaches is therefore explored. It is suggested that concepts and notions from the latter may contribute to the advancement of the conceptualization of action at a distance and agency in general in time-geography, as well as the incorporation of the immaterial realm into space-time diagrams. The resulting materially heterogeneous time-geography is a framework for studying the spacing and timing of different material entities that is sensitive to the role of artefacts and their local connectedness with other material forms. Some of its elements are illustrated briefly through an empirical study of the roles played by a few mundane artefacts in working parents' coping with childcare responsibilities on working days. The case study suggest that these artefacts not only enable goal fulfilment and routinization but also result in further spacing and timing practices, and can introduce uncertainty and novelty to existing orders.
\end{abstract}

Key words: time-geography, actor-network theory, work and caring responsibilities, Netherlands

'The importance of the social world is perhaps reasonably well understood. But to my knowledge, our 'communications' with things and what things means as agents in social situations are rarely examined.'

(Hägerstrand, 1984, p. 10)

'Objects are back in strength in contemporary social theory. ... a new world of materialities and objectivities has emerged with an urgency which has turned them into new sites of perplexity and controversy.'

(Pels et al., 2002, p. 1)

\section{Introduction}

Much has changed in human geography and social theory since the early 1980 s. The past decade has seen various yet divergent calls for a material (re)turn in geography, reflecting an increased unease with the discipline's focus on issues of meaning, representation and discourse (e.g. Philo, 2000; Lees, 2002). Although the very notions of matter and materiality as something opposed to culture or the immaterial are to be considered inadequate (Latham and McCormack, 2004), material geographies currently proliferate (Bakker and Bridge, 2006). They develop into multiple directions and draw on multiple sources, including social anthropology, feminist theory, and science, technology and society (STS) studies. In particular, actor-network theory (Latour, 1999, 2005) in the STS field has been influential. It has played an important role in the renewed interest in the geography of plants, animals and physical objects and landscape geography (Laurier and Philo, 2003; Hinchliffe et al., 2005), and stimulated geographers' thinking about agency and subject-object relations (Thrift, 1996).

Usually attempts to rematerialize geography do not (re)turn to traditional approaches for addressing the relations between human beings and the physical world surrounding them. And yet, an engagement with some "older" geographical work in particular Hägerstrand's time-geography might be useful to recent material geographies. While some may still think that time-geography only concentrates on constraints, is based on Cartesian space and Newtonian time and characterized by underdeveloped notions of power and agency (cf. Giddens, 1984; Harvey, 1990; Rose, 1993), Hägerstrand and co-workers sought to overcome many of these criticisms in the 1980s and 1990s (Lenntorp, 1999). In addition, Hägerstrand's interest in all physical materiality on the Earth's surface, the interdependence between human beings and inanimate material entities and the 'social' consequences thereof have not always been conveyed adequately in geographic textbooks and the writings of influential theorists. This is exemplified in major theorists' discussions of the coupling constraints concept. Originally defined as emanating from the human need to join other human beings, materials 
and/or artefacts for production, consumption or transaction (Hägerstrand, 1970), Giddens (1984, p. 114) described them as constraints 'that condition activities jointly with others' and Harvey (1990, p. 211) as 'the need to have the time-space paths of two or more individuals intersect to accomplish any social interaction'. Thus, the individual need to couple oneself to all kinds of inanimate entities has repeatedly been squeezed out of descriptions of what coupling constraints entail.

This is not to suggest that time-geography is without problems or shortcomings. For instance, while physical co-presence/absence and local connectedness are emphasized, the conceptualization of relations at a distance is underdeveloped in Hägerstrand's version of time-geography. His conceptualizations of agency, the role of material artefacts and the intersection of the material and immaterial realm may also be advanced. (Post) actor-network approaches appear to be a useful candidate for such advancement, because their ontologies are at least to some extent commensurable with timegeography (Gren, 2001; Thrift, 2005).

This paper explores to what extent time-geography may be combined with, and benefit from, insights from (post) actor-network approaches. Attention is focused on technical artefacts, because they can be used to extend the time-geographic conceptualizations of agency and action at a distance and show how local connectedness affects the durability of sociomaterial assemblages. The roles of a few artefacts are illustrated through a brief case study of how parents in dual-earner households space and time their work and caring responsibilities on working days with data from the Utrecht region, the Netherlands. The remainder of the paper starts with a description of time-geography, followed by a discussion of some insights and concepts from (post) actor-network approaches. The reader should keep in mind that neither of these bodies of work is homogeneous; both are variegated and do not constitute coherent wholes.

\section{Hägerstrand's time-geography}

Torsten Hägerstrand sought to provide a perspective $-\mathrm{a}$ worldview as he sometimes called it - on the ways in which all that exists on the Earth's surface gets placed or places itself during a certain period of time as an alternative to the increasing fragmentation and specialization of human geography (Hägerstrand, 2004). Time-geography as he envisaged it is process-oriented, concerned with move- ment and circulation of materiality, and accords a central role to touch as a sensory faculty and basic form of communication rather than speech and language (Gren, 2001; Pred, 2005). His interest in movement resulted in discomfort with conventional maps, which he sought to overcome through an alternative notation system - the time-geographic diagrams.

A detailed discussion of time-geography in the 1970s may be found in Parkes and Thrift (1980). Suffice it to say that time-geography started as a series of basic postulates about what human beings can(not) do and was built around the core concepts of the space-time trajectory, space-time constraints, and the project. The path or trajectory represents the movement of any physical entity through space and time, and is the outcome of the interactions between constraints and projects. Constraints were grouped into three basic types. In addition to coupling constraints, Hägerstrand (1970) identified capability and authority/steering constraints physiological and instrumental restrictions and laws, rules and norms regulating access to sections of physical space, respectively. Later a distinction was drawn between space-time constraints that are contingent and amenable to modification and basic conditions to which all interactions among animate and inanimate entities are subject (Hägerstrand, 1975). The latter include, for instance, the impossibility of two bodies or objects occupying exactly the same position in physical space at a given moment in time and the indivisibility of the human body. Simple as they may seem, these basic conditions have profound implications, including a presence/ absence binary: corporeal presence at one location implies absence elsewhere (Adams, 1995).

Projects were originally defined as clusters of acts, individuals and items necessary for the completion of any intention-inspired or goal-oriented behaviour (Hägerstrand, 1973). Attention for the project concept grew in Hägerstrand's later writings, in which he emphasized the importance of $l o$ cal connectedness and momentary 'thereness' of phenomena as determinants of the success of projects. Completion of a project requires room to be made within a landscape: a territory with its total filling of material and immaterial entities - human bodies and minds, animals, artefacts, words and other entities - that constitute the conditions for action. Rather than a visual or scenic panorama, it is a configuration of contacts between countless existents with their own biographies of encounters (Hägerstrand, 1995a). ${ }^{1}$ 
Projects are linked to the landscape through the (re)creation of pockets of local order: specific sections of the landscape equipped with material objects and systems of regulation facilitating the (repeated) performance of acts (Ellegård and Vilhelmson, 2004; Lenntorp, 2004). Ordering, for Hägerstrand, was the spacing and timing of bodies, artefacts and other items as parts of the landscape in a continuous attempt to protect a project from the intervention of unwanted influences, the double challenge of keeping favourable things and events within reach and unfavourable ones out of the immediate environment through a variety of interrelated strategies (Hägerstrand, 1974, 1984, 1988):

1. Transportation, or actually the enhancement of the speed of movement vis-à-vis that of other entities in the landscape;

2. Fixation, or the 'colonisation of the future' (1988, p. 40) whereby durable structures are created or used that provide protection within the landscape. These structures can be material or immaterial. Examples of the latter are promises and contracts;

3. Deployment of technologies, to overcome capability constraints and reduce the uncertainty immanent to projects through the standardization of acts.

As the opening quote of this paper and the previous paragraph suggest, Hägerstrand and associates explicitly acknowledged the importance of and empirically investigated material 'things' during a period when few human geographers were interested in materiality (Hägerstrand, 1974; Ellegård, 1983, 1996). They did so because they believed artefacts to mediate social structures and relations (Hägerstrand, 1995a). Implied in this statement is the suggestion that the physical is not simply material. Similarly, Hägerstrand (1989, p. 5, emphasis added) argued that:

Meaning and matter come together in the human person. Action in the landscape whatever the meaning is, is also matter acting on matter. Seen in this perspective actions become space/time trajectories of matter.

It is therefore possible to argue that, especially in his latest writings, the material and immaterial were entangled in one another for Hägerstrand. Rather than dualistically juxtaposing internal mental experiences and events in the outside world as in the 1970s,
Hägerstrand (1995a, b) was more interested in the intersections and overlap of the cultural and the material in the landscape. As the philosophical underpinnings of these endeavours, he used the Popper and Eccles scheme of the three worlds - the universe of physical entities; mental states; and products of the human kind (Hägerstrand, 2004).

Hägerstrand's conceptualization of agency seems to have developed over time. In the 1970 s agency tended to reside with humans, as the definition of the project concept exemplifies. While it can be traced in his texts from the 1970s, he argued more explicitly that agency is not necessarily related to intentionality, will and consciousness in the 1980s and 1990s. Drawing on Wittgenstein and others, he then emphasized how human beings interact with their surroundings through touch and everyday practices. Unlike earlier work (Hägerstrand, 1974), he later also considered artefacts to be imbued with some kind of agency, as the opening of this article suggests. And in one of his last papers Hägerstrand (1995a, p. 36) wrote:

it is striking how tightly the boundary is drawn around the actor. There is only a social context and this only in a very abstract form. Neither the actor nor his or her partners are considered as living bodies. And there are neither tools nor other things as support or as material to work on.

At least in Hägerstrand (1984), he argued that artefacts as agents not only enable people to overcome capability constraints but are also sources of routinization and stabilization, enhancing the predictability of projects. It should be added, however, that overall his texts do not suggest that he considered artefacts and other objects to be full-fledged actors; he continued to distinguish between causal events in nature and social actions by humans (Hägerstrand, 1995a). He also wrote about the 'life' of humans and 'existence' of animals, plants and artefacts (Hägerstrand, 1995b), thereby hinting at ontological differences in kind between people and the nonhuman entities populating the Earth's surface. One could say that Hägerstrand remained somewhat vague and undecided about the agentive capacities of the latter.

Arguably it is to the understanding of how the local connectedness of material forms constrains and enables 'social' processes that time-geography makes its largest contribution. Although Hägerstrand pointed out that landscapes are not necessar- 
ily local, time-geography could benefit from further conceptual development of the relations between material entities that are separated in physical space (cf. Adams, 1995). This, I believe, is important because processes such as globalization and technological advances have increased opportunities for action at a distance and reconfigured the meaning of the words near and far in everyday parlance and scientific discourse (Amin and Thrift, 2002; Callon and Law, 2004). At the same time, the fundamental corporeality Hägerstrand sought to highlight should not be discarded, as action at a distance always requires the physical bundling of people, artefacts and other material forms. Further, while addressing the role of everyday material artefacts, issues of agency and the relations between the material and immaterial in particular in his later work, Hägerstrand did so at an abstract level without recourse to empirical investigation. Consequently, it remains unclear how and why artefacts act as agents in social situations and can invoke change in existing orders. One way to address these issues is to draw on insights from (post) actor-network approaches and an empirical study of everyday objects used by dual-worker households to juggle work and caring responsibilities.

\section{(Post) actor-network approaches}

The term 'actor-network theory' (ANT) is commonly used to denote the work of Latour, Callon, Law and their colleagues. During the past years these researchers tended not to use this name, but Latour has recently re-embraced the term 'since the easiest signpost is the best' $(2005$, p. 9). In this article I employ the names "(post) actor-network approaches" or "(post) ANT" for the work of these STS writers, their colleagues and geographers inspired by them. It has become increasingly difficult to separate this field from other approaches, because what used to be known as ANT has been mingled with other post-structuralist currents, especially those inspired by the "vitalist" philosophy of Gilles Deleuze who reworked the ideas of Bergson, Spinoza and other philosophers. This blending of (post) ANT with other currents is perhaps best exemplified through non-representational theory in geography, for which Latour and associates are one source of inspiration alongside thinkers as diverse as Deleuze, Merleau-Ponty, Bachelard, Butler and Haraway (Thrift, 1996; Amin and Thrift, 2002). The genesis of actor-network thinking is well rehearsed by now (Murdoch, 2006) and will not be repeated here. Attention will instead be directed towards the (post) ANT contributions to thinking about ordering, materiality and agency.

Questions of ordering have always been central to (post) ANT, whereby ordering may be described as the coordination of a large heterogeneity of material and immaterial elements into specific spatiotemporal arrangements (Callon and Law, 2005). Time and again it has been contended that orders can be established in numerous ways and are always provisional; they are precarious achievements continuously liable to modification. There are none the less various ways in which orders can be given at least some degree of stability, including the deployment of technical artefacts such as measurement devices, texts and automatic door closers. Technologies such as these create (quasi) stability because they localize and globalize human interaction (Latour, 1996). They localize in the sense that they channel the possibilities for (human) interaction into specific directions; they globalize because they enable human beings to extend relations in space and time. By delegating interaction and other relations into nonhuman entities, humans can give obduracy and transportability to those relations. Artefacts are thus essential to action at a distance and long-distance control (Law, 1986). None the less, rather than functioning as simple intermediaries, technical artefacts translate intentions and mediate relations (Latour, 1999, 2005). Eventually, they may routinize sequences of (human) acts and indeed act as intermediaries, which often means that their role becomes invisible. Punctualization which occurs when a group of entities is seen as a single agent - is none the less reversible; intermediaries can always become mediators again.

Notions of agency are implied in the above discussion. According to (post) actor-network thinking, agency is not a capacity located within the human mind, but a precarious and emergent effect of the arrangement of heterogeneous materials (Callon and Law, 2005). Agency becomes possible if links are established and maintained among actants - human or nonhuman entities that modify other entities in trials (Latour, 2004). It is thus a characteristic circulating through assemblages of actants, or actor-networks. This view on agency is made possible by a monist ontology of force (Brown and Capdevila, 1999): there are basic units of substance (actants) that enter into relations and form assemblages through encounters. The implication is that there are only ontological differences in degree between human and nonhuman entities. 
Over time many criticisms have been levelled at ANT and its conceptualizations of ordering and agency of which three are most relevant here. First, the work of Latour and others has been criticized for privileging fixity over viscosity and highlighting the (re)production of hierarchies and domination at the expense of other ordering strategies. Feminists in particular have pressed this point, because they felt uneasy about the masculine managerialism and heroism characteristic of ANT. Haraway ([1997] 2004), for instance, has argued for greater sensitivity to other modes of ordering and the relevance of the prime axes of differentiation in society - gender, class and race - as explanatory factors in ordering practices. Second, the assumption that all elements (or actants) must have something in common and can potentially be related to one another makes it impossible to differ with networks and results in determinism (Lee and Brown, 1994). The third criticism concerns the replacement of differences in kind between humans and nonhumans with differences in degree. Geographers, including those sympathetic to ANT, have struggled with this move. Laurier and Philo (2003), for instance, argue that actor-network thinking downplays the role of human emotions and feelings - similar observations have been made with regard to time-geography (e.g. Buttimer, 1976) - and therefore hesitate to say that human beings and non-human entities are equivalent to one another. Other adherents of non-representational theory have also commented on ANT's technical inflection and argued that specific competences be accorded to human beings as members of networks, given their embodiment and the 'affectivity of (body) subjects' (Whatmore, 2002, p. 161; Thrift, 1999; Anderson, 2004). ${ }^{2}$ Critical geographers drawing on ANT have also questioned the equivalence of human and nonhuman actors, contending that social relations can exert more power than others (Castree, 2002; Kirsch and Mitchell, 2004). Finally, Murdoch (1998) argues that human beings are capable of renegotiating their positions within networks in ways unavailable to nonhuman beings, thereby suggesting that human and nonhuman actants sometimes differ in kind.

These criticisms have been addressed in several ways, which tend to emphasize the indeterminacy and openness of relations. Since the mid-1990s, a focus on fixity and closure has been traded for a stress on durability, potentialities and uncertainty in (post) ANT and related bodies of work (Callon and Law, 2005; Murdoch, 2006). John Law and colleagues have delved into topology and identified other spatialities, including fluids - materially heterogeneous associations without stable boundaries that lack a strong core or fixed structure and gently reshape their configurations akin to Deleuzian rhizomes (Law and Mol, 2001). Fluids also allow for feminine modes of ordering of persons 'willing to serve and observe, able to listen, not seeking control, but rather daring to give themselves over to circumstances' (De Laet and Mol, 2000, p. 253). Also drawing on Deleuzian philosophy, Latour (2004) has emphasized the unknown potential and recalcitrance of associations of actants. With respect to artefacts, he has employed the trope of the detour to argue that technologies and artefacts will undoubtedly result in modified intentions and uncertainty and thus in irony and paradoxes:

If you want to keep your intentions straight, your plans inflexible, your programmes of action rigid, then do not pass through any form of technological life. The detour will translate, will betray, your utmost imperious desires.

(Latour, 2002, p. 252)

Combining Deleuze/Bergson with the notion of the blank figure by Serres, Hetherington and Lee (2000) argue that there are certain elements within sociomaterial assemblages that hold these associations together because they are constitutionally underdetermined. These elements cause a slowdown in the circulation between (human) actors and make people wait, because it is not immediately obvious how they might be used within existing orders. It is in moments such as these that their virtuality - that which defies representation and is outside the network - is actualized and somehow becomes part of a sociomaterial association. ${ }^{3}$ Blanks allow for new connections and thus enable stability and change within sociomaterial assemblages. A parallel between blankness and agency may be drawn (Hetherington, 1997): because blanks do not necessarily follow pre-established programmes of action, they interrupt closures just as agency does. Brown and Middleton (2005) argue that humans are the blankest of all actors. Drawing on Deleuze/ Bergson, they also contend that fundamental differences between human and other actors exist, thereby recovering ontological differences in kind between human and non-human actors.

The work by Latour, Hetherington and others is in many ways comparable to that of Amin and Thrift (2002) and colleagues (e.g. Latham and Mc- 
Cormack, 2004) who have combined classic actornetwork theory with Deleuzian/Spinozian thought on the transhuman world. For them the human body is not a self-contained whole but a sociomaterial assemblage built out of other bodies and objects through which intensities circulate. Rather than passive relays maintaining life, objects as integrated into the body as some kind of organs can enhance the senses and constitute immanent forces of potentiality from which 'the new constantly proceeds' (Amin and Thrift, 2002, p. 91). They argue none the less that objects' multiplicity should not be overlooked; numerous artefacts direct us continually in ways we barely notice because they have become indispensable to our daily practices, consciousness and subjectivity.

It thus appears that recent work on artefacts provides a series of concepts helpful to the further development of Hägerstrand's time-geography. Notions such as delegation, mediation, detour and blankness may be used to rethink agency and change in time-geography and to expand the concepts of the project and pocket of local order. First, though, some remarks about the commensurability of (post) actor-network thinking and time-geography are in order.

\section{A matter of compatibility?}

A comparison of Hägerstrand's time-geography with the work of Latour and colleagues shows parallels beyond a shared interest in spacing and timing. Both are process-oriented and performative, highlighting actual practices, materiality and issues of transportation and transformation. Latour and Hägerstrand also share a clear scepticism about social theory. Further, there are some similarities in terms of the conceptualization of space and time. Both Hägerstrand (1988) and Latour (1997) have rejected Kantian views on space and time (albeit for different reasons) and argued that space and time should be accorded the same philosophical dignity. For both of them, space, time and matter/actants are intricately related. ${ }^{4}$

There are, however, a number of points where time-geography and (post) actor-network approaches diverge. One of these concerns agency. While both Hägerstrand and (post) ANT thinkers are critical of conceiving of agency as a purely conscious and intentional activity, they differ with respect to nonhuman agency. Where Latour (2004) gives nonhuman entities a voice and frees them from causal determination, Hägerstrand is more hesitant and ambivalent in this regard in his latest texts and tended to think of actors as strictly human in the 1970s. If, however, time-geography is to incorporate 'the social' more satisfactorily in its framework, its practitioners should abandon Cartesianism and go all the way to distribute agency more fully between human and nonhuman entities (Gren, 2001).

One might also think that the creativity and openness valued by Bergson, Deleuze and non-representational theorists is not commensurate with Hägerstrand's focus on constraints and physicality. Hägerstrand wrote somewhat sceptically about philosophy and social theory more than once, as he held the view that thinkers tended to lose sight of the practicalities of everyday life and the fact that there are space-time constraints conditioning the possibilities for action in the corporeal world of matter (Hägerstrand, 1988). ${ }^{5}$ However, as discussed before, Hägerstrand was not only interested in constraints. Especially in his later papers he argued that local connectedness is also enabling and that the landscape is 'always both a graveyard and a cradle of creation' (Hägerstrand, 1995b, p. 93). Further, the work of some geographers drawing on Deleuze has also been criticized for over-emphasizing spatial openness and fluidity and discarding fixities and blockages (Amin and Thrift, 2002; Marston et al., 2005).

Still, it could be contended that some versions of time-geography are mechanical in a Bergsonian sense, treating change and evolution merely as the realization of pre-existent possibilities ${ }^{6} \mathrm{~A}$ case in point would be the analysis of the space-time prism - the set of possible trajectories that could have been taken given a set of space-time constraints, which Hägerstrand $(1970,1975)$ considered an important tool for investigating which projects and paths failed and which has been rediscovered by transport planners and employed to expose the gender blindness of conventional accessibility measures (Kwan, 2004). However, later versions of time-geography have a less mechanical character and approaches drawing on Deleuzian thinking and Hägerstrand's worldview are not mutually exclusive. This is among others because a focus on openness and indeterminacy can contribute to our understanding of what happens within the limits of possibility set by Hägerstrand's constraints. Such a focus may also enable researchers to better understand how the impacts of space-time constraints are creatively circumvented and relaxed in everyday practices (cf. Schwanen, 2006). 
Finally, time-geography and (post) actor-network approaches appear to differ with respect to the use of micro/macro and local/global distinctions. While readers of Hägerstrand's texts may come across these dualisms regularly, their use as explanatory categories has been criticized repeatedly by Latour and others. However, Hägerstrand sought to provide a notation system that eliminated the macro/micro gap in order to enable a better understanding of the implications of (macro level) physical planning decisions for individuals and social structures (Gren, 1994; Ellegård, 1996). Further, when criticizing Giddens for failing to show how structures and individual action are related, Pred (1981) drew on time-geography to overcome this problem. In other words, time-geography is not necessarily caught up in the micro/macro dualism.

Overall, then, the differences between time-geography and (post) actor-network approaches tend to be smaller than Hägerstrand's most renowned texts from the 1970 s might suggest. There are, I believe, sufficient common grounds for combining these fields. Where differences exist, concepts from one field may enrich the other.

\section{Towards a materially heterogeneous time- geography}

Concepts and notions from time-geography and (post) actor-network approaches can now be reassembled into what might be termed a materially heterogeneous time-geography. It follows from the discussion thus far that the words 'materially heterogeneous' are actually superfluous. I use them to emphasize that Hägerstrand's interest in materiality beyond human corporeality has often been overlooked and to accentuate that time-geographers need to grant material entities additional qualities. Where Hägerstrand was undecided in terms of the agentive capacities of nonhuman entities, it is also possible to grant artefacts a kind of agency that is not associated with intentionality or consciousness but their ability to link up with other actants (including human beings). At the same time, human beings should be accorded an exceptional ontological position; they differ in kind from nonhuman actants because of their reflexive and affective capacities and unique sensory faculties.

I will illustrate that time-geography may overcome some of its weaknesses with respect to action at a distance and agency through (post) ANT notions and concepts by discussing a series of mundane artefact which parents in dual-worker families use in their everyday juggling of work and caring tasks. More specifically, I will concentrate on artefacts travelling into/out of a nursery when parents deliver/collect their children on regular weekdays. The information about these artefacts and parents' use of nurseries was collected during fieldwork in the Utrecht region, the Netherlands. ${ }^{7}$ The focus is here on nurseries because they play a key role in working parents' daily lives. Their children spend considerable time there, and this regularly imparted feelings of guilt in some of the parents interviewed, especially the mothers. There is none the less scant attention for nurseries as sites of childcare in the human geography literature. Before discussing the artefacts travelling into/out of the nursery, I will return to the concepts of the project and pocket of local order.

\section{Projects and pockets of local order}

Recall from earlier sections that Hägerstrand originally defined projects as clusters of acts, individuals and items required for the completion of any intention-inspired and goal-oriented behaviour. (Post) ANT terminology may be used to reduce the implicit human centredness in this early definition. A project may also be defined as a set of actions performed by an association of materially heterogeneous elements working together to fulfil one or more goal(s) or intention(s) on the part of at least one of the entities involved, which may or may not change with the passage of time. The entities that are or become part of a project are close to one another in network/fluid space, irrespective of their positioning in physical space. Their relational proximity derives from the fact that they are somehow relevant to the fulfilment of the goal(s) and intention(s) associated with the project. The pocket of local order concept also needs to be refined, because 'local' can have a double meaning: it can refer to corporeal proximity (touch) in Hägerstrand's space of matter and to relational proximity (function) in network/fluid spaces. Pockets of local order can thus stretch across physical space; corporeal proximity is, however, always involved because pockets need to be (re)produced within broader landscapes where numerous other projects also try to secure room.

The differences between the two project definitions may seem minimal. Note, however, that the second definition does not automatically relate goals and intentions to human beings. This is not to suggest that inanimate entities have goals and inten- 
tions themselves but rather that these entities may reflect the delegated intentions and goals of actants in other spaces and times, making those absent actants incorporeally present at the sites where the entities in question are located physically (Latour, $1997,1999)$. One way to incorporate goals, intentions and other immaterial phenomena into time-geographic diagrams would thus be to depict the space-time trajectories of nonhuman entities.

As the above suggests, technical artefacts should be considered important constituents of projects and pockets of local order. This is because artefacts are indispensable to human behaviour; human agents usually have to associate themselves with artefacts to overcome capability constraints (Hägerstrand, 1984, 1988) and make action possible (Latour, 1999, 2005). In addition, both Hägerstrand and classic ANT texts (e.g. Law, 1986) have pointed at the routinising and stabilising impact of artefacts, maintaining that these contribute to the transportability and fixation of relations and phenomena. Because of the routinisation they enable, the relevance of artefacts for human (inter)action is usually overlooked (Hägerstrand, 1984; Latour, $1999,2005)$. This also occurs with respect to what travels into/out of the nursery. One tends to think of children as corporeal entities delivered in the morning and collected in the evening and forget the artefacts that come and go with them - think of lunchboxes, (spare) clothes, nappies, baby chairs, toys and the like. Further, technical artefacts allow humans to act at a distance and mingle absence and presence. Finally, and this is where Hägerstrand and Latour and associates diverge, technical artefacts can result in detours requiring additional ordering or spacing and timing and introduce novelty into existing orders.

\section{Transportability and speeding up}

Some artefacts travel into/out of the nursery with the children but are less directly related to the interactions between infants and the centre's staff members. Various parents leave child seats which can be disassembled from bicycles at the nursery in the morning and reassemble them on their bikes when picking up their children. The interviews suggested that parents do this because it enables them to traverse the landscape on the way to/from their workplace more easily, thereby enhancing their relative speed when travelling through the city at morning/evening peak hour. This in turn made it easier to commute longer distances within con- strained time budgets and increased parents' - and especially mothers' - access to suitable employment.

Ruth, a mother residing in the city of Utrecht, related how she and her husband were both able to commute to a workplace outside the city when their two sons were still infants because they shared not only chauffeuring responsibilities but also child seats. In the morning she brought her two infants to the nursery on her bicycle and left the child seats, for which there is a small storage room, in the nursery building. Afterwards she would return home, take the family car and drive to her work. At the end of the workday, her partner who commutes by train to another major Dutch city would pick up the children, riding his bike from the station to the childcare centre. There he would assemble the seats on to his bicycle and take the children home. Ruth and her partner left the seats at the nursery because he used a folding bike, which he took along on the train and unfolded when getting off the train to travel to his office. Travelling by folding bike from the train station to the office is faster than using public transport in the city where he is employed.

Rick, another interviewee, also shares chauffeuring duties with his wife. Like Ruth he leaves the seats for his two children at the nursery in the morning, so that his wife can use them later that day. Dropping the seats at the centre saves time: without the rather expensive seats he can leave his bike at an unguarded bicycle shed near the entrance of the train station - notorious for the theft of bicycles instead of putting it in a guarded shed at greater walking distance from the railway track.

These examples may strike readers as specific if not peculiar, ${ }^{8}$ but illustrate an aspect normally overlooked in studies of dual-earner households' juggling of work and caring tasks: technical artefacts such as removable child seats play an important part in enabling mothers and father to combine work and caring responsibilities and to overcome capability constraints restricting (mothers') jobs access to locations near the home. This is not to suggest that negotiations about gender roles between partners, the renegotiations of norms and values about parenthood in formal and informal locales, or the mobilization of social networks are ordering strategies of little use to dual-earner households (e.g. Jarvis et al., 2001; Wheelock et al., 2003). These are all very important but cannot fully explain how parents combine work and domestic duties, because the material everyday practices are left out of consideration. 
Although it may appear that the bikes and child seats function as intermediaries usefully assisting parents in fulfilling goals, they mediate actively and provide the sociomaterial assemblage of bikeparent-child seat-child with space-time trajectories it did not have or conceive of before. Further, as Rick's case illustrates, use of the child seats - instrumental to a seamless combination of work and caring responsibilities - also adds complexity to his spacing and timing practices, for he has to leave them at the nursery or park his bike in a guarded shed at a greater distance from the station entrance. Otherwise breakdown of this particular assemblage will almost certainly be the outcome.

\section{Action at a distance}

Other artefacts enable parents to globalize themselves and make them both bodily absent and incorporeally present in the nursery. They thereby effectively resolve the presence/absence binary characteristic of time-geography (Hägerstrand, 1975; Adams, 1995). Two kinds of items are particularly important in this process of delegation: mobile telephones and notebooks.

The interviews made clear that telephone access is a major issue for both the parents and the nursery staff. The latter want to be able to reach the children's parents (or alternatively relatives or friends) at all times just in case something is wrong with the child. Parents want to be available continuously should a nursery staff member phone them. Therefore, many interviewees carry their mobile phones with them during all activities at their workplace, including meetings and lunch in the canteen, even though this sometimes results in mental conflicts whereby they ask themselves whether it is appropriate to leave their phones switched on. These parents are thus continuously engaged in the creation and negotiation of a local pocket of order within the broader office landscape, so that they can hear and/ or touch their mobile phone if required. This local ordering exemplifies a technical detour (Latour, 2002), an unintended outcome of the mediation of the mobile phone. At the same time, it is also a parent ordering her local surroundings and managing the local connectedness of the phone and her own body, so that she can act incorporeally at a distance if required. She is thus actively engaged in the mingling of distance and proximity and in the (re)creation of a pocket of order that stretches across physical space.

The gendered nature of this mediation process should not be overlooked (cf. Haraway, 1991). The interviews suggest that especially, though not exclusively, mothers use the mobile phone to mingle distance and proximity. As a consequence, their family lives are extended into their work projects and traditional gender division of labour within households may endure despite mothers' larger participation in the labour force. In fact, the use of the mobile phone described here is one manifestation of what is known as remote mothering in communication studies (Rakow and Navarro, 1993; Lemish and Cohen, 2005).

Mediation by artefacts also occurs at the nursery, as the notebooks used by parents and staff members exemplify. When bringing the children in the morning, parents hand a diary or notebook with background information and instructions for the day to a staff member. During the day the staff (can) record events related to the child. It may be said that parents delegate themselves into the notebook before bringing the child to the nursery, and make themselves - or rather their opinions and intentions - available at multiple sites in physical space so that they can act in space-times of which they are not corporeally a part.

The notebooks frequently act as stabilizers in that nursery staff members consult them to see what the parents want them to do and then act accordingly. Such a state of closure is, however, not selfevident, since staff members may also act in ways that differ from the parents' intentions. Perhaps a staff member does not fully understand the text and interprets it differently. While cognitive factors may explain why the parents' intentions are transformed, their translation may also reflect the blankness of the notebook itself (Hetherington and Lee, 2000). In the nursery, where a group of children may continuously be demanding the staff's attention, the notebook and text it contains may obtain a different meaning than, say, at the breakfast table. This is because it connects in different ways to the material forms locally present and hence influences the spacing and timing in the nursery building in ways not anticipated by the parents. Interestingly, the parents - and nursery staff members - seemed to be aware of the blankness of the notebooks. Some parents explained that they often clarify the textual instructions in the notebooks verbally to the centre's staff members when delivering the children in the morning (even when pressed for time). They thus try to influence the spacing and timing on the basis of the notebook later that day. The possibility of surprises in the ordering process remains 


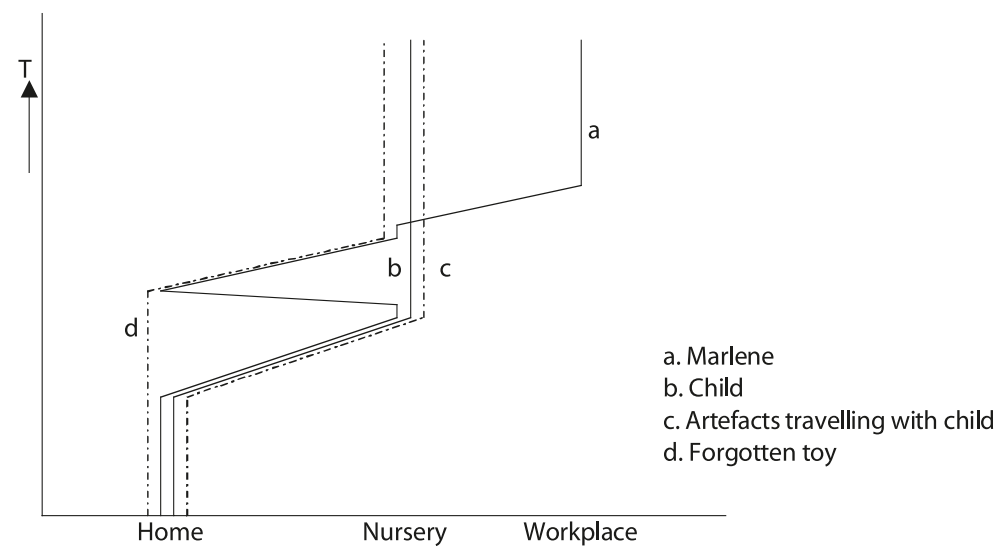

Fig. 1. A time-geographic diagram. among others however, because the parents cannot foresee the local connectedness of the notebook later that day.

\section{Precarious spacing and timing}

While the relevance of technical artefacts in daily practices is often overlooked, it becomes more visible when punctuality is disrupted and artefacts fail to do their job. ANT texts frequently illustrate such a situation with examples of mechanical defects (Latour, 1999, 2005). The process of punctuality can, however, also be disrupted if artefacts are not appropriately spaced and timed as parts of pockets of local order in the landscape; detours in goals can also occur when heterogeneous entities in the landscape are out of touch.

These points may be illustrated by Marlene's remarks about her second child's cuddle toy. When rushing towards the nursery in the morning, her other son's elementary school and her own work location, she and her youngest son sometimes forget the toy and leave it at home. Being afraid the child won't be able to sleep at midday, she usually returns home after bringing her other son to school, collects the toy, delivers it to the nursery, and drives to her workplace where she arrives 10 to 15 minutes late. As before, a technical artefact mediates human action at multiple sites in physical space at various moments in chronological time and for several people. The artefact in question - a means for letting the child experience an absent familiarity in the nursery through touch (Hetherington, 2003) - becomes an end in itself (Latour, 2002). It should be noted that the cuddle toy causes a detour even though Marlene's time resources are very limited. During the interview Marlene emphasized repeat- edly how determined she is to arrive at her workplace in the morning as early as possible. If she arrives there early, she can leave earlier in the afternoon, will worry less about whether she can work as many hours that week as she is supposed to do, and will feel less concerned about how her (male) colleagues think about her working hours and loyalty to her employer.

It is important to appreciate that not only Marlene acts but so does the toy. She returns home because the toy at home is out of reach of her child and therefore an object without identity. It becomes something if her child can touch it - for him but also for her. If the toy is not with her child, she is likely to feel anxiety and guilt while commuting and working: will my child be able to sleep? What kind of a mother am I to leave my child at the nursery without his favourite toy? Therefore she puts herself in the service of her child and the toy. When placed within reach of her child, the blankness of the toy becomes functional (Hetherington and Lee, 2000); the toy can then contribute to the successful completion of Marlene's work-related projects and the nursery's projects in subsequent moments that day. While not determining the roles of blank objects in any straightforward manner, attending to their local connectedness may shed some light on the roles they might attain.

The role of the toy can be appreciated more clearly if a time-geographic diagram is drawn (Fig. 1). ${ }^{9}$ If , as is normally done, only the trajectories of human beings were depicted in the space-time diagram, Marlene's path would have been incomprehensible. Once the artefacts that (are supposed to) travel with the child are added to the diagram, the detour in her path becomes easier to understand, since it serves to bring the toy as a blank object in 
touch with her child. Note that the diagram provides a symmetrical representation of what happens (Thrift, 2005). It does not ascribe agency to Marlene, the toy or any other entity, but simply shows the importance of the local connectedness of human and nonhuman entities and the effort required for creating and maintaining this.

Figure 1 illustrates another point. Recall from earlier sections that Hägerstrand sometimes dualistically juxtaposed the material against the immaterial. If the (outside) world of matter and an (inner) world of language and meaning are considered as two disjointed spheres, it would indeed be difficult to incorporate the immaterial in time-geography (Gren, 2001). If, however, Latour's (1999, ch. 2) arguments about 'circulating references' are followed, it becomes easier to include the immaterial into Hägerstrand's notation system. Latour argues that matter and language should not be seen as separate spheres and offers an alternative to the conventional model of correspondence between world and language, consisting of chains of material elements with specific forms. It is through these chains that phenomena circulate. In effect, Latour has replaced differences in kind between matter and language by differences in degree.

Latour's model may be combined usefully with Hägerstrand's diagrams. On the one hand, the circulation of phenomena often requires that heterogeneous material forms are brought together (before some are transported to other space-times) and Hägerstrand's diagrams may be used to track this process of circulation. On the other - and this is directly related to Fig. 1 - Latour's ideas may be used to argue that notions of good parenting and associated affects are indirectly present in the diagram rather than being external to it (cf. Amin and Thrift, 2002), because they circulate through the coupling and uncoupling of the various space-time trajectories - the mother's path rejoining that of the toy which is then reunited with the child's trajectory and stays so after his mother has embarked on her commuting trip. Paradoxically, turning more physical may enhance time-geography's abilities to deal with the social realm (Gren, 2001).

\section{Reflections}

Some of the things I have tried to say in this paper may be recapitulated through a series of suggestions. First, time-geography is not only about constraints and/or the visualization of space-time paths but also about the ordering of heterogeneous mate- rial entities (cf. Hägerstrand, 1974; Ellegård, 1983). That many have considered time-geography as concerned with human beings and the paths traced out by their bodies is largely reflective of scientific practice of the 1970s and 1980s when there was less interest in materiality than nowadays. Second, therefore, current thinking in geography opens up new possibilities for extending time-geography. As this paper has elaborated, an engagement with notions from (post) ANT and related post-structuralist approaches that give more emphasis to norms, emotions and affects can assist time-geography in better understanding the role of material objects in the performance of projects, the (re)constitution of pockets of local order and the unfolding of spacetime paths. In this way, the focus on local connectedness in the landscape may be supplemented with more attention for action at a distance; the conceptualization of agency can be advanced; the corporeal presence-absence binary can be dissolved; and the social realm can be dealt with in new ways.

Third, the case study suggests that the mundane objects travelling into/out of a nursery discussed here play multiple roles. They are useful in engendering action and the overcoming of capability constraints, although this often comes at the price of additional spacing and timing in the landscape. They can also contribute to the stabilization and routinization of projects. Further, there are artefacts that enable humans to act incorporeally at a distance through delegation, though here too, extra spacing and timing may be required to maintain the capacity to do so. The outcome of action at a distance is nevertheless uncertain because of the blankness of the artefacts used to delegate one's intentions and goals. Finally, artefacts may disrupt routines if not spaced and timed appropriately whether or not they hold heterogeneity together depends very much on their position in the landscape.

Fourth, (post) ANT may in some ways benefit from time-geography. Although Latour, Law and colleagues have shown how globalities and universitalities are produced locally, their work might benefit from considering how objects come to hang together locally with other entities present and absent in the landscape and how local connections bear on the durability and reach of sociomaterial assemblages. Thus, time-geography would provide a framework for analysing how and why artefacts must and can change shape while travelling through space and time and how encounters with the local landscape affect its performance and fluidity (cf. De Laet and Mol, 2000). 
Fifth, the empirical part has revealed two main points with respect to the literature about parents' everyday juggling of work and caring tasks. While developments in norms and values about parenting and the mobilization of social support mechanisms are essential to the combination of work and caring duties, nonhuman artefacts also play an important part which is usually ignored. At the same time, the use of artefacts can easily result in additional ordering that adds further complexity and uncertainty to the already busy schedules of dual-earner families. They may thus contribute to situations of time squeeze even if they are employed to alleviate these. The continuity of this ordering process remains seriously underexposed in time-budget studies. Even feminist-geographic studies of women's double burden of paid and domestic work and the recent stream of studies of the work/life balance largely fail to highlight the spacing and timing of humans and artefacts.

Finally, I believe that time-geography can be relevant to rematerialized geographies. It is imperative that geographers continue to advance their own thinking by drawing on theoretical developments in related disciplines. They should be careful, however, not to overlook the legacy of their own discipline, part of which can provide insights and notions that might be useful to contemporary issues and research interests. It can only be hoped that this paper will trigger further and renewed interest in Hägerstrand's work.

\section{Acknowledgements}

The supportive suggestions of the anonymous reviewers are gratefully acknowledged. The work reported in this paper is financed by the Netherlands Organization for Scientific Research (NWO), grant 451.03 .058 .

\section{Notes}

1. It is in the conceptualization of the links between landscape and project that Hägerstrand's debt to the continental chorographic tradition in geography becomes most visible (cf. Olwig, 2002).

2. This neglect of feelings and affects implies that (post) actornetwork thinking could never have been the only source of inspiration for non-representational theorists who have become increasingly interested in the "utter ubiquity of affect as vital elements of cities' and everyday life (Thrift, 2004, p. 57).

3. Deleuze's virtuality is a reworking of Bergson's notion of duration. Virtuality is something that exists but not in actuality. Think of genetic information (May, 2005): it is stored in our genes and contributes to our growth but cannot be experienced by humans directly. Virtual objects can only be known through the actualization of their effects, in this case the growth and ageing of our bodies.

4. Gren (1994) argues that Hägerstrand's conception of space has changed from absolute (a container) to relative (outcome of an ontology of matter) over time. Likewise, his conception of time evolved from time as a chain of instants moving forward in an undifferentiated manner to time as 'embedded in the situational permutations of matter in space' (Hägerstrand, 1988, p. 34).

5. The criticism that social theory failed to foreground practices has also been raised by Thrift (1996) and formed one of his motivations for exploring what is now known as nonrepresentational theory.

6. Bergson argued that science tended to treat evolution as the realization of preformed possibilities and deprived it of inventiveness and creativity, because scientists think in closed systems, where the possible is derived by abstracting from the real and then projected backwards (Pearson and Mullarkey, 2002). In his opinion, true creativity can only be approached when attending to duration (or virtuality in Deleuze's terms). The virtual differs in two ways from the possible (May, 2005). First, the virtual exists even though humans cannot experience it directly. Second, the virtual does not mirror the real but is instead absolutely different and/or new.

7. In total, forty parents residing in the city of Utrecht and surrounding suburban settlements logged their activities for one day in a diary and were interviewed by the author about the reported activities and the juggling of work and domestic responsibilities in general. Respondents include men and women with varying numbers of children in specific age classes and residing in residential neighbourhoods at different distances from Utrecht's city centre. The majority of these adults were recruited via two day-care centres (one within and one outside the municipal boundaries of Utrecht) during on-site visits by the author and through letters. Information obtained during on-site visits has also been used for this paper. The data were collected in September 2004 to February 2005.

8. It should be remembered that the bicycle is the second most important mode of travel after the private car in the Netherlands, and the second most important access/egress mode (after walking) when train constitutes the main travel mode (Krygsman, 2004). Although no statistics are available, it is not uncommon to take folding bikes on trains in the Netherlands. Nor is it odd to leave child seats at the nursery; interviews and on-sites visits suggest that more parents do this (very) regularly.

9. It goes without saying that this diagram is not intended to provide a totalizing master vision from a point of nowhere by a 'neutral' intellectual subject (Haraway, 1991). It should instead be seen as a sensitizing device (Hinchliffe et al., 2005), alerting the reader to the relevance of the toy and its local entanglements.

Tim Schwanen

Department of Human Geography and Planning

Faculty of Geosciences

Utrecht University

P.O. Box 80.115

3508 TC Utrecht

The Netherlands

E-mail: t.schwanen@geo.uu.nl 


\section{References}

ADAMS, P.C. (1995): 'A reconsideration of personal boundaries in space-time', Annals of the Association of American Geographers 85 (2): 267-285.

AMIN, A. and THRIFT, N. (2002): Cities: Reimagining the Urban. Polity Press, Cambridge.

ANDERSON, B. (2004): 'Time-stilled space-slowed: how boredom matters', Geoforum 35 (6): 739-754.

BAKKER, K. and BRIDGE, G. (2006): 'Material worlds? Resource geographies and the "matter of nature", Progress in Human Geography 30 (1): 5-27.

BROWN, S.D. and CAPDEVILA, R. (1999): 'Perpetuum mobile: substance, force and the sociology of translation', in LAW, J. and HASSARD, J. (eds): Actor Network Theory and After. Blackwell, Oxford, pp. 26-50.

BROWN, S.D. and MIDDLETON, D. (2005): 'The baby as virtual object: agency and difference in a neonatal intensive care unit', Environment and Planning, D: Society and Space 23 (5): 695-715.

BUTTIMER, A. (1976): 'Grasping the dynamism of lifeworld', Annals of the Association of American Geographers 66 (2): 277-292.

CALLON, M. and LAW, J. (2004): 'Introduction: absence - presence, circulation, and encountering in complex space', Environment and Planning, D: Society and Space 22 (1): 3-11.

CALLON, M. and LAW, J. (2005): 'On qualculation, agency and otherness', Environment and Planning, D: Society and Space 23 (5): 717-733.

CASTREE, N. (2002): 'False antitheses? Marxism, nature and actor-networks', Antipode 34 (1): 111-146.

DE LAET, M. and MOL, A. (2000): 'The Zimbabwe bush pump: mechanics of a fluid technology', Social Studies of Science 30 (2): 225-263.

ELLEGÅRD, K.(1983): Människa-produktion. Tidsbilder av ett produktionssystem. University of Gothenburg, Gothenburg.

ELLEGÅRD, K. (1996): 'Reflection over routines in time and space - actors' interaction ands control in a work place context', Österrreichisches Zeitschrift für Soziologie 21 (2): 235 .

ELLEGÅRD, K. and VILHELMSON, B. (2004): 'Home as a pocket of local order: everyday activities and the friction of distance', Geografiska Annaler: Series B, Human Geography 86 (4): $281-296$

GIDDENS, A. (1984): The Constitution of Society: Outline of the Theory of Structuration. University of California Press, Berkeley, CA.

GREN, M. (1994): Earth Writing: Exploring Representation and Social Geography In-between Meaning/Matter. University of Gothenburg, Gothenburg.

GREN, M. (2001): 'Time-geography matters', in MAY, J. and THRIFT, N. (eds): TimeSpace: Geographies of Temporality. Routledge, London, pp. 208-225.

HÄGERSTRAND, T. (1970): 'What about people in regional science?', Regional Science Association Papers 24 (1): 7-21.

HÄGERSTRAND, T. (1973): 'The domain of human geography', in CHORLEY, R.J. (ed.): Directions in Geography. Methuen, London, pp. 67-87.

HÄGERSTRAND, T. (1974): 'On socio-technical ecology and the study of innovations', Etnologica Europaea 7 (1): 17-34.

HÄGERSTRAND, T. (1975): 'Space, time and human conditions', in KARLSQVIST, A., LUNDQVIST, L. and SNICKARS, F. (eds): Dynamic Allocation of Urban Space. Saxon House, Westmead, pp. 3-14.

HÄGERSTRAND, T. (1984): 'Escapes from the cage of routines: observations of human paths, projects and personal scripts', in
LONG, J. and HECOCK, R. (eds): Leisure, Tourism and Social Change. Dunfermline College of Physical Education, Edinburgh, pp. 7-19.

HÄGERSTRAND, T. (1988): 'Time and culture', in KIRSCH, G., NIJKAMP, P. and ZIMMERMAN, K. (eds): The Formulation of Time Preferences in a Multidisciplinary Perspective. Avebury, Aldershot, pp. 33-42.

HÄGERSTRAND, T. (1989): 'Reflections on "What about people in regional science?"', Papers of the Regional Science Association 66 (1): 1-6.

HÄGERSTRAND, T. (1995a): 'Action in the physical everyday world', in CLIFF, A.D., GOULD, P.R., HOARE, A.G. and THRIFT, N.J. (eds): Diffusing Geography: Essays for Peter Haggett. Blackwell, Oxford, pp. 35-45.

HÄGERSTRAND, T. (1995b): 'Landscape as overlapping neighbourhoods', in BENKO, G.B. and STROHMAYER, U. (eds): Geography, History and Social Sciences. Kluwer Academic Publishers, Dordrecht, pp. 83-96.

HÄGERSTRAND, T. (2004): 'The two vistas', Geografiska Annaler: Series B, Human Geography 86 (4): 315-323.

HARAWAY, D. J. (1991): Simians, Cyborgs, and Women: The Reinvention of Nature. Routledge, New York.

HARAWAY,D. ([1997] 2004): 'Modest_Witness@Second_Millennium', in HARAWAY, D. (ed.): The Haraway Reader. Routledge, London, pp. 223-250.

HARVEY, D. (1990): The Conditions of Postmodernity. Blackwell, Cambridge, MA.

HETHERINGTON, K. (1997): 'Museum topology and the will to connect', Journal of Material Culture 2 (2): 199-218.

HETHERINGTON, K. (2003): 'Spatial textures: place, touch, and praesentia', Environment and Planning 35A (11): 1933 1944.

HETHERINGTON, K. and LEE, N. (2000): 'Social order and the blank figure', Environment and Planning, D: Society and Space 18 (2): 169-184.

HINCHLIFFE, S., KEARNS, M.B., DEGEN, M. and WHATMORE, S. (2005). 'Urban wild things: a cosmopolitical experiment', Environment and Planning, D: Society and Space 23 (5): 643-658.

JARVIS, H., PRATT, A.C. and WU, P.C.C. (2001): The Secret Life of Cities. Prentice Hall, Harlow.

KIRSCH, S. and MITCHELL, D. (2004): 'The nature of things: dead labour, nonhuman actors, and the persistence of Marxism', Antipode 36 (4): 687-705.

KRYGSMAN, S. (2004): Activity and Travel Choice(s) in Multimodal Public Transport Systems. Utrecht University, Utrecht.

KWAN, M.P. (2004): 'GIS methods in time-geographic research: geocomputation and geovisualization of human activity patterns', Geografiska Annaler: Series B, Human Geography 86 (4): 267-280.

LATHAM, A. and MCCORMACK, D.P. (2004): 'Moving cities: rethinking the materialities of urban geographies', Progress in Human Geography 26 (6): 701-724.

LATOUR, B. (1996): 'On interobjectivity'. Mind, Culture, and Activity 3 (4): 228-245.

LATOUR, B. (1997): 'Trains of thought: Piaget, formalism, and the fifth dimension', Common Knowledge 6 (3): 170-191.

LATOUR, B. (1999): Pandora's Hope: Essays on the Reality of Science Studies. Harvard University Press, Cambridge, MA.

LATOUR, B. (2002): 'Morality and technology: the end of the means', Theory, Culture and Society 19 (5/6): 247-260.

LATOUR, B. (2004): Politics of Nature: How to Bring the Sciences into Democracy. Harvard University Press, Cambridge, MA.

LATOUR, B. (2005): Reassembling the Social: An Introduction to Actor-network-theory. Oxford University Press, Oxford. 
LAURIER, E. and PHILO, C. (2003): 'The region in the boot: mobilising lone subjects and multiple objects', Environment and Planning, D: Society and Space 21 (1): 85-106.

LAW, J. (1986): 'On the methods of long-distance control: vessels, navigation and the Portuguese route to India', in LAW, J. (ed.): Power, Action and Belief: A New Sociology of Knowledge? Routledge \& Kegan Paul, London, pp. 234-263.

LAW, J. and MOL, A. (2001): 'Situating technoscience: an inquiry into spatialities', Environment and Planning, D: Society and Space 19 (5): 601-621.

LEE, N. and BROWN, S.D. (1994): 'Otherness and the actor network: the undiscovered continent', American Behavioral Scientist 37 (6): 772-790.

LEES, L. (2002): 'Rematerializing geography: the "new" urban geography', Progress in Human Geography 26 (1): 101-112.

LEMISH, D. and COHEN, A.A. (2005): 'On the gendered nature of mobile phone culture in Israel', Sex Roles 52 (7/8): 511 521.

LENNTORP, B. (1999): 'Time-geography - at the end of its beginning', GeoJournal 48 (3): 155-158.

LENNTORP, B. (2004): 'Path, prism, project, pocket and population: an introduction', Geografiska Annaler: Series B, $\mathrm{Hu}$ man Geography 86 (4): 223-226.

MARSTON, S. A., JONES III, J. P. and WOODWARD, K. (2005): 'Human geography without scale', Transactions of the Institute of British Geographers NS 30 (4): 416-432.

MAY, T. (2005): Gilles Deleuze: An Introduction. Cambridge University Press, Cambridge.

MURDOCH, J. (1998): 'The spaces of actor-network theory', Geoforum 29 (4): 357-374.

MURDOCH, J.(2006): Post-structuralist Geography. Sage, London.

OLWIG, K. R. (2002): "The duplicity of space: Germanic "Raum" and Swedish "rum" in English language geographical discourse', Geografiska Annaler: Series B, Human Geography 84 (1): 1-17.

PARKES, D. and THRIFT, N. (1980): Times, Spaces and Places: A Chronogeographic Perspective. Wiley, Chichester.
PEARSON, K.A. and MULLARKEY, J. (2002): Henri Bergson: Key Writings. Continuum, New York.

PELS, D., HETHERINGTON, K. and VANDENBERGHE, F. (2002): 'The status of the object: performances, mediations and techniques', Theory, Culture and Society 19 (5/6): 1-21.

PHILO, C. (2000): 'More words, more worlds: reflections on the cultural turn and human geography', in COOK, I., CROUCH, D., NAYLOR, S. and RYAN, J. (eds): Cultural Turns/Geographical Turns: Perspectives on Cultural Geography. Pearson Education, Harlow, pp. 26-53.

PRED, A. (1981): 'Social reproduction and the time-geography of everyday life', Geografiska Annaler: Series B, Human Geography 63 (1): 5-22.

PRED, A. (2005): 'Hägerstrand matters: life(-path) and death matters - some touching remarks', Progress in Human Geography 29 (3): 328-332.

RAKOW,L. and NAVARRO, V.(1993): 'Remote mothering and the parallel shift: women meet the cellular phone', Critical Studies in Mass Communication 20 (3): 144-157.

ROSE, G. (1993): Feminism and Geography: The Limits of Geographical Knowledge. Polity Press, Cambridge.

SCHWANEN, T. (2006): 'On arriving "on time", but what is "on time"', Geoforum 37 (6): 882-894.

THRIFT, N. (1996): Spatial Formations. Sage, London.

THRIFT, N. (1999): 'Steps to an ecology of place', in MASSEY, D., ALLEN, J. and SARRE, P. (eds): Human Geography Today. Polity Press, Cambridge, pp. 295-322.

THRIFT. N. (2004): 'Intensities of feeling: towards a spatial politics of affect', Geografiska Annaler: Series B, Human Geography 86 (1): 57-78.

THRIFT, N. (2005): 'Torsten Hägerstrand and social theory', Progress in Human Geography 29 (3): 337-340.

WHATMORE, S. (2002): Hybrid Geographies. Sage, London,.

WHEELOCK, J., OUGHTON, E. and BAINES, S. (2003): 'Getting by with a little help from your family: toward a policyrelevant model of the household', Feminist Economics 9 (1): $19-45$. 